\title{
Review of The Library Outreach Cookbook
}

\section{Geraldine Kalim}

University of Georgia

Abstract: Review of Sittler, R.L. \& Rogerson, T.J. (Eds.) (2020). The library outreach cookbook.

Chicago: Association of College and Research Libraries. 217 pp.

Keywords: outreach, patrons, stress relief, community, campus, holiday, celebration, marketing

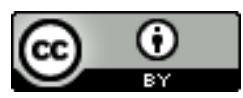

This is an Open Access article distributed under the terms of the Creative Commons Attribution 4.0 International License (http://creativecommons.org/licenses/by/4.0), which permits unrestricted use, distribution, and reproduction in any medium, provided the original work is properly cited. 
At 110 chapters, a prospective reader could be forgiven for being entirely overwhelmed by the idea of this book. But after reviewing the Table of Contents, readers likely will be relieved to see how specific the chapters are. After reading through the book once, readers can pick up this book months from now and easily flip to the exact scenario on which they need guidance. Need therapy dog inspiration? Flip to Chapter 85. Want to create a Women's History Month display? Turn to Chapter 56.

The idea of a cookbook inspires confidence and gives the impression that the authors have gone through these processes before and will have written, tested, and improved these "recipes" for the reader's benefit. The reader can come along, get some inspiration, plan some outreach, and have the wisdom, experience, and creativity of the authors behind her. The librarian may even be inspired to include her own spin or flourish on the outreach, and because she is a librarian, she will find ways to pay that additional wisdom and experience forward. These recipes are invaluable compilations of ingredients, cautions, diagrams, instructions, and more. This book exemplifies one of the best aspects of librarianship - the willingness to share wisdom not only with patrons, but with colleagues as well. Let's put on our chef's hats and get to work!

This book is organized logically into four sections: Getting Started with Outreach, CampusFocused Outreach, Community-Focused Outreach, and General Programming Activities and Events. These sections allow the reader to use this resource going forward as a reference guide, quickly flipping to the section that addresses their present needs. Each section is further divided, making it necessary to review the Table of Contents before jumping into the book. The practice of outreach often feels overlapping, but the editors have successfully sorted chapters into buckets like marketing, swag, K-12, stress relief, and also by patron group (e.g., students, faculty, community). 
Taking a look at the chapter contributors' short biographies in the back of the book, the reader sees that this compilation benefits from a wide variety of perspectives from librarians and staff members, some who have marketing or outreach in their titles, and some who do not. Some contributors have an MLIS and some do not, others have law degrees or doctorates, some are deans or directors, and the contributors come from a variety of library types. This broad convening speaks to the strengths of this book and the perspectives it offers. In many cases, the authors have listed their email addresses so the reader can follow up, which is further evidence of the collaborative nature of these contributors.

It is possible your library already does some of the ideas that this book offers. One may nevertheless find it helpful to review those sections to get a feel for how others have pulled off a therapy dog event or a movie night. There is always room for improvement, simplification, or a new way of thinking about outreach.

Entries such as "Aligning Library Marketing and Communications with Institutional Branding" can have a wide appeal across library types. This recipe specifies steps to a process that can sometimes feel confusing and amorphous. After reading this section, one may realize there is a more methodical path to take.

Much of the content in this book is the type of information or guidance that one might wish were written down somewhere but seems like the kind of information one may only learn from experience or from asking around. For example, "Collaboration within a Social Media Working Group" memorializes an otherwise potentially mysterious part of outreach. The advice here would apply to someone who already is a member of a group, or to someone who wants to start this type of group. 
Features that could enrich a future edition or perhaps a companion title are case studies and examples. A great example of this within the text is "Regram and Repost." Figure 13.1 features an example Instagram post. The figures within "Discovering and Creating a Unique Marketable Space" are also entertaining, creative, helpful examples of how the authors put their advice into practice. A future edition of the Cookbook also could include testimonials from libraries that successfully (or not so successfully) experimented with some of the ideas and advice in this book.

Fans of this Cookbookcan seek out some of the other titles, such as The first-year experience cookbook and The critical thinking about sources cookbook. 